\title{
Algumas Palavras sobre a Minha Experiência na Pace Law School ${ }^{1}$
}

\author{
Miguel Augustin Kreling ${ }^{2}$
}

\author{
"Quando a última árvore for cortada \\ e oultimo rio envenenado, \\ vamos nos dar conta de que dinheiro não alimenta." \\ (Autoria desconhecida)
}

Gostaria de começar este relatório reconhecendo que a grande oportunidade que tive de estudar nos Estados Unidos deveu-se à ajuda que recebi dos meus amigos, professores e familia. Sou imensamente grato a todos que me ajudaram a ter essachance e a tirar dela o melhor proveito. Seique poderei estar sendo injusto ao nomear apenas alguns; que me perdoem os que forem vítimas de minha ingratidão. As pessoas sem as quais a expetiência que passo a relatar nas linhas seguintes não teria sido possível, entre muitas outras, sãoo Alexander Wooldridge, a Alexandra Pretto, a Ana Gerdau Borja, a Antonia Espíndola Longoni Klee, o Diego Lemer, o Felipe Dick, o Jason Bailey, o Jay Bischoff, a Laura Miller, o Lucas Lixinski, a Luciana Quinto, a Maitê Schmitz, o Rafael Ribeiro, assim como a Profa. Dra. Claudia Lima Marques, o Prof. Dr: Cezar Saldanha, a Profa. Dra. Catherine Tinker, a Profa. Dra. Silvia Rocha, a Profa. Dra. Véra Fradera, o Prof. Dr Carlos Zanini, oProf. Dr. Cláudio Michelon, e os meus pais, o Carlos Kreling e a Vânia Kreling, e a minha irmã, a Mariana Kreling. Essas pessoas foram incansáveis, estiveram lá quando eu precisei, tiveram paciência comigo nos momentos de dúvidase incertezas, deram-me apoio nos momentos dificeise ajudaram-me a tomar decisöes e fazer as escolhas certas. A todos, a minha eterna gratidão.

Oconvênio com a Pace University ${ }^{3}$ proporcionou-me uma verdadeira experiência de vida. Dela não tirei apenas conhecimentos e habilidades, mas também, e principalmente, conviç̧ões e paradigmas. Se alguém me perguntasse o que eu mais aprendi com este intercâmbio, euresponderia:

\footnotetext{
${ }^{1}$ Gostaria de agradecer ao Programa de PósmGraduação em Direito da Universidade Federal do Rio Grande do Sul, em especial à pessoa da Profa. Dra. Claudia Lima Marques, por dar-me esta grande oportunidade de poder compartilhar com a nossa comunidade, mediante a presente publicação, algumas palavras a respeito da grande oportunidade que tive de estudar na Pace Law School.

2 Sou aluno do oitavo semestre do Curso de Graduaçăo em Direito da Universidade Federal do Rio Grande do Sul. Fui bolsista CAPES-FIPSE na Pace Law School, Withe Plains, no Estado de Nova lorque, de 19 de janeiro a 24 de maio de 2004. Sou muito grato pela oportunidade de ter sido bolsista.

${ }^{3}$ Apesar de o principal campus estar sediado em Manhattan, na Cidade de Nova lorque, a Faculdade de Direito da Pace encontramse em White Plains, ainda no Estado de Nova lorque, 25 minhas ao norte da Cidade.
} 
a conviçãa de que a educação é o principal meio pelo qual se pode mudaro destino de umpovoe o paradigma de como se pensa o direito na familia jurídica anglo-saxã e como se ensina o direito na América do Norte. Acredito que esta experiência provará ser de muita valia à minha aspiração de tornar-me, provera a Deus, um professor. Sinto-me comprometido a retribuir, fazer frutificar e levat adiante oinvestimento que os povas brasileiro e note-americano fizeram em nam, mediante a concessão das bolsas. Assim, sou grato a todo povo brasileiro e norte-americano e, em especial, à Fundação Coordenação de Aperfeiçoamento de Pessoal de Nivel Superior, à Universidade Federal do Rio Grande do Sul, ao Fund for the Improvement of Postsecondary Education eà Pace University.

Neste relatório, tenho dois objetivos principais: (i) prestar contas emrelação ao aproveitamento da oportunidade de estudar na Pace Law School; e (ii) tecer algumas consideraçöes sobre a common law e o ensino jurídico nos Estados Uniclas. Se a consecução de algum desses objetivos, no julgamento de alguém, não for satisfatótia, coloco-me à disposição para prestar qualquer informação adicional.

\section{[-Do Aproveitamento da Oportunidade}

Na Pace Law Shcool, realizei precipuamente as seguintes atividades:

SubjectCourse TitleCreditsCrade

Spring 2004LAW 856 Environmental Law Survey3.00 A. LAW 745 Corporations \& Partnerships4.00 A-LAW 657 Securities Regulation3.00 A POL 395 Independent Study In Political Studies $3.00 \mathrm{~A}$

Na disciplina Independent Study in Poltical Studies, escrevi um trabalho em matéria de direito ambiental econstitucional norte-ameticano, intitulado:

The Envirommental Power of the Commerce Clause: An Interstate Commerce Burden on Enwiromental Law?

Cuida-se da fonte e estrutura constitucionais do direito ambiental norte-americano; em particular, de uma análise de como a Cláusula de Comércio da Constituição dos Estados Unidos, enquanto fonte principal do direito ambiental norte-americano, limita ou não, em virtude de sua própria natureza, o desenvolvimento do direito ambiental norte-americano. A perspectiva adotada tempor premissa fundamental oentendimento de que sem um meio-ambiente sacio eecologicamente equilibrado não pode haver uma vida cconomicamente produtiva nem comércio entre os Estados. ${ }^{4} \mathrm{O}$ propósito último do trabalhoé visłumbrar uma solução constitucional que permita e potencialize o desenvolvimento desimpedidoe natural do direito ambiental nonte-americanoconforme às inclinaçöes

"It appears that while a traditional commonplace is that economic prosperity is inherently environmentally unfriendly, the federal environmental legal system is constitutionally predicted precisely on the opposite assumption - that commerce among States cannot be maintained and enhanced unless the environment is preserved. Indeed, under a broader perspective there is no doubt that the maintenance of the Earth's life supporting natural system is a precondition to the very continuance of human life and, a fortiori, of the general social welfare achievaole through the unencumbered practice of commerce." 
democráticas do povo norte-americano e de uma forma imune às distorçōes político-institucionaise eao lobby dos interesses econômicos de curto prazo. Trata-se de um tema que deve preocupar a todo anbientalista, por ter implicações que permeiam todo o direito ambiental, assim como aos constitucionalistas que velem pela representação político-institucional adequadae simétrica da vontade geral do povo. Pela orientação que me deram na pesquisa e elaboração do trabalho, agradeço à Professora Catherine Tunker, ao Professor Nicholas Robinson, ao Professor Jefrey Miller e ao Professor Lee Paddock.

Nesta mesnra disciplina, coordenada pela Profa. Dra. Catherine Tinker, tivemos a oporturidade de assistrit, na Organização das Naçōes Unidas (ONU), aos trabalhos da 12 a Sessão da Comissão sobre Desenvolvimento Sustentável sobre o tema Água, Sarieamento e Habitaçäo Humana, que ocorreu entre $14 \mathrm{e} 30$ de Abril de 2004. Durante a Conferência, o Tinker Institute on Intemational Law and Organizations (THLO) ea Union Internationale des Avocats (UIA) organizaram umevento paralelo, na ONU, intitulado Cross-cutting Linkages: Enabling Conditions for Sustarizable Development, que contou, entre outros palestrantes, como Chefe da Seção de Tratados da ONU, Dr: Palitha Kohona, o Diretor do Departamento Ambiental do Banco Mundial, Dr. Warren Evans, a Vice-Presidente Sênior da Fundação das Nações Unidas, Dr. Melinda Kimble. Agradeço à Profa. Dra. Catherine Tinker por esta oportunidade ímpar.

Quantoàs demais disciplinas que cursei, gostei de todas; os professores eram muito competentes: o Professor Nicholas Robinson, em Environmental Law Survey; o Professor James Fishman, em Corporations \& Partnerships; e a Professora Barbara Black, em Securities Regulation. Todos eles receberam-me muito beme colocaram-se à disposiçăo para ajudar-me. Mas o que eu mais gostei foi que todos esses professores trataram-me como um igual, não fizeram qualquer distinção entre mime os meus colegas norte-americanos, de tal forma que eu me senti incluído no meio. Também gostei muito da ênfase que eles deram à ética profissional no exercício das profissōes jurídicas.

Em relação ao conteúdo programático de cada disciplina que cursei, seguem as seguintes súmulas:

Environmental Law Survey. Panorama de Direito Ambiental Norte-Americano. O Direito Ambiental tomou-se uma parte integrante da vida cotidiana em quase todas as áreas de atuação profissional no direito hoje nos Estados Unidos. Este curso oferece uma introdução à estrutura básica das principais leis ambientais federais e à maneira como o jurista as encontra na prática (a Lei de Política Ambiental Nacional, a Lei das Águas Limpas, a Lei dos Ares Limpos e leis sobre materiaise resíduos sólidos e perigosos). Ao longo do curso, problemas de responsabilidade profissional são incluídos na consideração da substância de cada lei. Este cursoé un curso de base para as disciplinas ambientais especializadas mais avançadas e oferece ao generalista una compreensāo sólida do sistema legislativo, administrativo e judicial do Direito Ambiental contemporâneo. A avaliaçã̃o é um exame final de quatro horas de duraçãocom toda a matéria Três livrossão obrigatórios: Glicksman, Markell, Mandelker;

\footnotetext{
${ }^{5}$ Os seguintes artigos de doutrina, entre outros, amparam a asserção feita no texto: McConnell, Michael W., Federalism: Evaluating the Founders' Design, 54 U. CHI. L. Rev. 1484 (1987); Deborah J. Merritt, Commerce!, 94 Micr. L. Rev. 674 (1995); Merrit, Deboran J., The Guarantee Clause and State Autonomy: Federalism for a Third Century, 88 Colum. L. Rev. 1 (1988); Donald H. Regan, How to Think about the Federal Commerce Power and Incidentally Rewrite United States v. Lopez, 94 Mict. L. REv. 554 (1995).
} 
Tarlock, \& Anderson, Enwronmental Protection: Law and Policy, $4^{\text {th }}$ Edition, 2003, Aspen Publishers, New York, 1.070 p. (casebook); Selected Enwirmmental Law Statutes, 2003-2004 Educational Edition, West Publishers, 1.400 p. (statute book); ejoln Cronin \& Robert Fennedy, Jr, The Riverkeepers: Tuo Activists Fiont to Reckim Our Environment as a Basic Human Right, First Touchstone Edition 1999, New York, 302 p. A disciplináéaltamente técnica. A carga de leitura semanalé intensa, ultrapassando, com certa freqüência, uma centena de páginas densa e detalhadamente escritas. O Professor Robinson enfatizou as perspectivas diversas das três partes que freqüentemente se contrapöem nas disputas anbientais: da agência reguladora en matéria ambiental, da empresa con interesses econônicos e dos cidadãos preocupados com o meio ambiente. O Professor Robinson também focou as diferentes estratégias, tanto judiciais quanto extra-judiciais, de que o jurista ambientalista pode lançar mão no exercício probssional O Rofessor Robinson tem um amplo conhecimentogerale de direitocony̧arado, cita o Brasil em suas aulas e trás muitas infomações adicionais, de caráter não-jurídico, para ilustrar os problemas ambientais jurídicos. Ele éo menos socrático dos professores que tive. Foi a disciplina mais challenging (desafiante) que fiz, em razão da extensão, variedade e tecnicidade do conteúdo abordado. Ela deixou-me fascinadopelo Direito Ambiental.

Corporations \& Partnerships. Direito Societário Norte-Americano. Este é um curso básico sobre sociedades anônimas. Abarca a constituição de una sociedade, a alocação de poderese controle entre diretores, administradores e acionistas, o sistema de proxy, a sociedade de capital fechado e mecanismos de controle, os deveres dos diretores e outros "insiders" e a interaçāo entre os direitos sccietários federale estadual. Este curso também oferece un panorama sobre o direito das sociedades civis. A avaliação é um exane final de quatro horas de duração com toda a matéria. Quatro livtos são obrigatórios: Melvin A. Eisenberg, Corporations and Other Business Organzizations: Cases and Materials, $8^{\text {th }}$ Edition, 2000, Foundation Press, New York, 981 p; Melvin A. Eisenberg, Corporations and Odter Business Organizations: Cases and Materials, 2003 Suqplement, Foundation Press, New York, 278 p; Klein, Ramseyer, \& Bainbridge, Busmess Associations: Agency, Pantnershitis, LLCs, and Contorations, 2003 Statutes and Rules, Foundation Press, New York, 303 p; e New York Corporation Law, 2004 Whitebook, LexisNexis, 932 p. A disciplina é baseada, em grande parte, em common law (isto é, jurisprudência), de diversos Estados, em especial, de Delaware, New York, Massachusettse Califontia. Éuma disciplina pesada, especialmente para quem não gosta de business. Oexame é tido, pelos alunos, como un dos mais difíceis da Law School. O Professor Fishman procura colocar a matéria jurídica dentro de uma perspectiva prática e contextualizada na Corporate America. Lança mão de muitos recursos eletrônicos, como CALle Twen. Achoque aprendi muito neste curso.

Securities Regulation. Regulação Federal de Valores Mobiliarios. Este curso cobre o direito federal le as regras da Securities and Exchange Commission (SEC) quanto à emissão e comercialização de valores mobiliários, bem como os aspectos legais e infra-legais da indústria de valores mobiliários em geral. Tem por pré-requisito Cortorations \& Partnerships. Permitiram-me que eu cursasse ambas as disciplinas simuttaneamente. A avaliação consiste em: (i) dois trabalhos, emque se analisa odesempenho operacionale financeiro de uma sociedade anônima de capital aber to norte-americana, à escolhado aluno (eu fiz sobre a General Electric Company), com base, principalmente, no ammal retort e proxy statements da respectiva empresa e $10-\mathrm{K}, 10-\mathrm{Q}$ e $8-\mathrm{K}$ reports, que aempresa envia (periodicamente) à SEC; (ii) um exame final de 3 horas com toda a matéria. Dois livros são obtigatónios: Cox, Hillman, \& 
Langevoort, Securties Regulation: Cases and Materials, $3^{\text {nd }}$ Edition, 2001, Aspen Publishers, Gaithersburg, 1.288 p.; eJohn C. Coffee, Jr \& Joel Seligman, Federal Securties Laws: Selected Statutes, Rutes and Forms, 2003 Edition, Foundation Press, New York, 2.021 p. A Professora Black deu especial ênfase à responsabilidade profissional do advogado ao lidar con valores nobiliários e ao Sarbanes-Oxkey Act. Também pela contribuição de três colegas que trabalhavam naárea, o curso nãose limitou a aspectos jurídicos, mas deu uma idéia boa sobre o funcionamentoe regulação do mercado de valores mobiliários nos Estados Unidos, sendo um bom complemento a Cortorations 8 Partnerships. É uma disciplina pesadae, engrandeparte, extremamente técnica. A Professora Blacké muito boa, com una excelente didática, mas é tida pelos alunos como uma hard-grader (dificilmente dá nota alta),

\section{II-Consideraçães Gerais sobre o Direito o onsino do Direito nos Estados Unidos}

Gostaria de dividir com os que tiverem interesse algumas impressões e idéias acerca da common law e do ensino do direito nos Estados Unidos. É claro que a minha experiência foi pessoal, curta e limitada ao que pude observar enquanto aluno, por um semestre, na Pace Law School. As minhas observaçöes, igualmente, podem ser um pouco influenciadas pela minha experiência anterior na Inglaterra. Apesar dos problemas inerentes ao método indutivo, especialmente cuando a experiência concreta da qual se parte tenha suas limitaçöes naturais, acredito que as idéias a serem ventiladas a seguir possam ser de alguma valia àqueles que se precxupam com o direitoe o ensino juridico no Brasil emgeral.

A expressăo common law tem duas acepçôes principais; pode referir-se tanto à familia jurídica anglo-saxã quanto à jurisprudência ou case law. Neste relatónio, o significado predominante que se dá à expressão é o da familia jurídica; quando não for ocaso, haverá explicitação. Cuide-se também que, muitas vezes, ao referir-me a common law, estarei me referindo, na verdade, à common law norteamericana.

Nas considerações que desenvolvo a seguit, tomo a liberdade, com todo o respeito e a data maxima venia, de incluir algumas críticas ao direito e aos juristas brasileiros em geral, sem qualquer intento de atingir a alguém em particular. Trata-se de críticas de ordem sociológica. Considero-me a primeira víuina de min has próprias críticas. Sou brasileiroe, por isso, sou atingindo por tais críticas tanto quanto, ou mais de, qualquer outro compatriota. Acredito que sem crítica, não há perspectiva de melhora; e sem perspectiva de melhora, não há sentido para a vida. Considero-me também estar no dever de fazer as críticas que seguem; afinal, para que o povo brasileiro investiu tanto dinheiro na minha educação? Veja essas críticas da perspectiva de um brasileiro de coração, que ama o seu próprio país, que não trocaria por nada, que se vê no dever de lutar e trabalhar em prol dele; de um brasileiro que se retorce de dor com cada injustiça que se comete neste país; de um brasileiro que chora de amor com cada conquista que se logra no nosso país. Lutar pelo desenvolvimento do meu país é a missão da minha vida,

O exíguo diálogo entre a common law e a civil law. Gostaria de começar observando que a common law e a civil law são dois mundos diferentes, por vezes, incomunicáveis. Das centenas de decisôes norte-americanas que tive a oportunidade de ler, encontrei apenas uma que mencionasse personagens típicos da civil law: Justiniano, Puffendorf e Barbeyrac. Cuida-se, entretanto, de um 


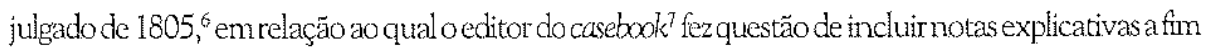
de esclarecer aos estudantes norte-americanos que não se tratava de nomes de juízes ingleses, mas sim de "civil law jurisconsulus". Na Inglaterra, não me deparei com nenhuma decisão que citasse a alguma fonte (authority) continental. Por outro lado, a doutrina brasileira (e, talvez, a continental em geral) raramente cita a cases ingleses, norte-americanos, canadenses, australianos, neozelandeses, indianos etc (embora nem tão raramente cite a autores da common law). Contrastantemente, o diálogo entre a doutrina brasileira e as doutrinas alemá, francesa, italiana, portuguesa, espanhola, suíça, belga etc, é considerável. Diálogo comparável observa-se dentro da famitia da common law -a qual engloba muito mais páses do que nós imaginamos (só da Commonuedulth participam 54 países). OJudicial Commintee of the Privy Council, por exemplo, que integra o direito constitucional inglês e reúne-se em Londres, tecebe apelações do Court of Appeal of New Zealand, do Supenior Counts das Províncias canadenses, do Supreme Court dos Estados australianos, assim como de outros países, comoda Índia, Paquistão, Chipre, Gana, Nigéria, Sri Lanka, Malta e Malásia. ${ }^{9}$ Se o diálogo dentro da civil law ocorre a título de compartithamento de experiências, o diálogo dentro da common lau parece irmáis longe, preocupandose inclusive com a harmonização jurisprudencial (tendência em que os Estados Unidos nãose incluem, entretanto). Essa tendência - do diálogo intra-sistema-parece-me natural, principalmente em razăo dos distintos sistemas de fontes. Contudo, parece-mequepoderíamos aprender bastantese procurássemos aumentaro diálogo entre sistemas, em particular, entre aciull law e a common kaw. Acho queo convênio FIPSE-CAPES entre Universidades brasileiras e norte-americanas tem desempenhado e pode desempenhar um papel impontante no sentido de aumentar o profícuo diálogo entre os sistemas.

O papel da "doutrina" no direito norte-americano. Na common law, não há doutrinadores (comalgumas exceçöes, como Blackstone), mas comentadores ${ }^{10}$. Os comentadores (istoé, a doutrina) não se citam muito entre si, mas se referem mais aos julgados judiciais. Não se trata apenas de citar ementas, como ocorre bastante no Brasil, mas sim, e principalmente, de narrar os fatos relevantes (material facts) docaso e apor-Ihes a solução juclicial. Éque o direitoestá vinculado aos fatos; alterandose estes, pode (ounão) alterar-se aquele. Opapel da doutrina, rectus, dos comentadores, é antes a de tentar conciliar os julgados judiciais (tarefa em que, em boa parte das vezes, não obtêm êxito), ou criticar-Ihes a solução, sem qualquer pretensão de dizer ou fazer Direito. Mas isso não quer dizer que não haja bons comentadores; bem pelo contránio, a "doutrina" (scholarly unitmegs ou scholarship) tende a ser criativa, inovadora, sofisticada e profunda, especialmente aquela que logra publicação nas law reviews das Universidades mais tradicionais.

\footnotetext{
${ }^{6}$ Pierson v. Post, 3 Cai. R. 175 (N.Y. Sup. Ct. 1805), Supreme Court of Judicature of New York.

'Casner, Leach, French, Korngold, Vanderveide, Cases and Text on Property, $4^{\text {th }}$ Edition, 2000. Aspen Publishers, Gaithersburg, p. 23-29.

${ }^{8}$ Nota-se, contudo, que o avanço no processo de integração da União Européia tenderá a promover um maior diálogo entre o direito inglês e o continental. Observei essa tendência na àrea de propriedade intelectual, vez que se busca harmonizar os direitos de patente e os direitos autorais, entre outros, a fim de conferir-lhes uma proteçäo mais abrangente, a nivel comunitário. Fol a única ocasião em que observei um juiz inglês levar em consideração uma decisão alemă, embora aquele discordasse radicalmente desta.

${ }^{9}$ Paul Jackson and Patricia Leopold, $O$. Hood Phillips and Jackson Constitutional and Administrative Law, $8^{\text {th }}$ Edition, 2001, Sweet \& Maxwelt, London, p. 807-816.

${ }^{t c}$ Commentators.
} 
O valor do Professor na comunidade jurídica norte-americana. Os professores norteamencanos, que produzem boa parte dos papers (artigos de doutrina), tendem a fazer jus à palavra professor, ou melhor, ao respeito que a palavia professor, na língua inglesa, (ainda) impöe. Eessa "carga" de reverência não é exclusiva do inglês norte-americano; o mesmo se dá no inglês britânico. $\mathrm{Na}$ Universidade de Westminster, em Londres, toda a vez que eu chamava o meu professor de tributário de Professor Earle, ele me conigia: "Don't call me Professor... I'mateacher". Eolha que euo colocariaentre os cinco melhores professores que eu já tive na minha vida. O título de professor, nos Estados Unidos, dispensa o de mestre ou doutor. Só tenchances de tomar-se professor o aluno (i) que tenha um histórico escolar impecávele (ii) que se forme numa das Universidades mais renomadas (comalgumas exceçōes), especialmente as que integram a hry League." "Quem não consegue ser admitido numa Universidade dessas, provavelmente terá que se contentar com a profissão de advogado ou outra, mas não poderá almejar à de professor. Examine-se, por exemplo, as Universidades em que estudaram os Justices da Suprema Corte dos Estados Unidos: a maioria formou-se em Harvard ou Yale (mas a University of Texas está representada!). Parece-me razoável que da lite intelectual de um país, dentre os mais preparados e competentes, saiam os professores;é, contudo, interessantecomonós, no Brasil, nem sempreparecemos partilhar dessa mesma crença.

A sofisticaçäo científica da doutrina norte-americana e o entendimento generalizado de que Ciência é tuma coisa, já Direito é outra. Uma característica da doutrina norte-americana que me encantou é de como ela é sofisticada e aberta para as demais ciências, inclusive as exatas. Responda-me uma coisa: quantos doutrinadores brasileiros você conhece que enpregam teorias aritméticas, geométricas, estatísticas, anuariais, sociológicas, econômicas, políticas, da física quântica, para explicaro direito? Como há, na doutrina norte-americana, idéias novas e criativas, teses ousadas e desafiadoras; un discurso que não se legitima pela repetição e pelo argumento de autoridade, mas sin pela justificação polínicaou filosófica transcendente; uma técnica menos voltada à interpretação das normas do que às policy reatsons e policy choices por trás delas; uma preccupaçẫo acadêmica menos centrada na consistência interna, teónica (ou tetónica) de suas teses do que na eficácia externa, social de suas soluçóes; uma doutrina preocupada menos coma conveniência política de suas teses do que com o valor objetivo da dialética científica. Sinceramente, nunca tinha visto antes um direito tão "cientificizado", tăo dialogante com as denais ciências, tão aberto para a vida e para o mundo; e, ao mesmo tempo, tão modesto, sem jamais pretender ser, ele mesmo, uma Ciência. Parece-me que, no Brasil, dá-se precisamente o contrário: enquanto nós clamamos que o Direito é uma Ciência, nós isolamo-lo das demais ciências, tomamo-loincomunicável, não the questionamos suasínúmas conviçốes; acreditamos que o Direito tenha una lógica própria, fechada, hermética; que tenha um sentido autônomo, una razão de ser en si epor si, que independa, por vezes, até mesmo, dos efeitos sociais que produz ao ser implementado. Para os norte-americanos - e esse me parece ser o entendimento generalizado dos operadores do direito ${ }^{12}-0$ direito nada mais é do que um instrumento, um meio pelo qual se implementam políticas públicas. O direito não tem um sentido imanente, mas o que lhe deu o

11 Princeton, Harvard, Yale, Columbia, Dartmouth, Brown, Penn, \& Cornell.

12 Não, é claro, dos que se debruçam sobre o problema, os quais oferecem diferentes teorias. 
seu criador, seja o juiz, seja o Congresso. De nada serve o direito senão para produzir na sociedade os efeitos visados pelos policymakers. Acredita-se, por fim, que os juristas não são cientistas e que os cientistas não são juristas.

A influência dos cursos pré-jurídicos na sofisticação da doutrina norte-americana. Mas por que seráque a douttina norte-americana é tāo sofisticada, tão aberta as demais ciências? Só consigo ver uma razão: os juristas norte-americanos não são só juristas, mas juristas e algo mais, muitas vez, cientistas. Na minha turma, por exemplo, eu tinha colega que eram químicos, historiadores, politólogos, ambientalistas, lingüistas, literários, economistas, administradores, engenleiros, artistas, dos que lembrei em perguntar o que haviam feito antes da Law School. Faculdade de Direito nos Estado Unidosé pós-graduação. Ninguémlápode estudar direito sem antes ter se formado em outrocurso, seja este o que for: Assim, na Law Schoole na vida jurídica hápessoas com os mais diversas backgroundse formaçóes. Nãopoderia ser maior, dessa forma, a pluralidadee diversidade de idéias e teorias. Cada um, ao colocar a sua fomação anterior a serviço do direito, está, na verdade, contribuindo para a evolução do direito, para o seu aperfeiçoamento, para que o direito se torne socialmente menos apático e economicamente mais responsável. Essa caractetística da doutuina norte-annericana, não observei, por exemplo, na Inglaterta, onde os juristas são, como no Brasil, só juristas.

Nos Estados Unidos náo se desconfia tanto das teorias econômicas aplicadas ao direito quanto no Brasil. Deixe-me deixar betn claro qual é a minha posição pessoal a respeito do tema. A minha posiçāo não é a de que as teorias econômicas aplicadas ao direito devem prevalecer; mas sim a de que elas - como quaisquer outras teorias sérias - merecem ser ouvidas, consideradas, sopesadas, especialmente em um ambiente acadêmico democrático, que valoriza a pluralidade de idéias e de métodos. Énatural que as teorias econômicas tenham a sua própria orientação axiológica, isto é, que dêem certa importância ao interesse social do desenvolvimento econômico. A minha posição é a de que o interesso social do desenvolvimento econômico é um interesse não desprezivel na gama de interesses que o direito tenta conciliar e nos quais busca inspiração ao fazer suas escolhas políticas (policy choices). Parece-me que o direito norte-ameticano concilia razoavelmente bem os frutos da pesquisa jurídica e os da pesquisa econômica. Acredito que o estudo do direito norteamericano - un direito que me parece estar mais atento, eser mais sensivel, à conjuntura econômica - pode-se trirar liçóes úteis àqueles que almejam viabilizar condiçóes de vida dignas a todos os brasileiros; afinal, não se pode falar em efetivação dos direitos humanos, sem crescimento econômico sustentável.

Os juízes e os tribunais ocupam uma posição mais elevada na hierarquia das fontes formais do direito. Os juizes năo citam muito os comentadores, mas sim os precedentes, mesmo que estes näo tenham precedential wahue, istoé, năo sejam law, mas sesde que tenham certa autoridade, em razão da reputação ou da graduação do juiz ou do tribunal. Uma decisãoé law, istoé, vinculante, se tiver sido, em relação ao juiz que a invoca, prolatada por un tribunal superior que tenha, naquele caso, competência recursal. Das decisões da Suprema Corte dos Estados Unidos que tive a oportunidade de ler durante os cinco meses em que estudei direito norte-americano, encontrei menos de uma dezena que fez referência a un ou outro comentador. Quando se organizain conferências acadêmicas, as principais atraçōes tendem a ser os juízes, e não os professores ou comentadores. Ademais, frases como "segundo Pontes de Miranda, o locatário tem direitoa..." não se encontram nas decisões ou nos artigos de doutina norte-americanos, mas sim "segundo Wilsonv. Christchumch, olocatáro tem direito a..." Essa 
legitimidade dos juizes está, obviamente, fundada em razóes hitórico-culturais. Mas se saliente que os juźes norte-americanos (e os ingleses também) de primeiro grau tendem a ser mais pudentes e menos temerários do que alguns de seus colegas brasileiros. Parece-me que só a prudência dálegitimidade e, por conseqüência, autoridade e poder: Toda a vez que se abusa do poder-como se observa noexemplo que algunsjuizes de primeira instância no Brasil que se rebelam contra o direito pátrio e deliberadamente passam a prolatar sentenças em discordância com oentendimento consolidado das tribunais superiores - perde-se o poder: Parece-me que é por isso que os juízes norte-americanos preferem exceder-se no lado do conservantismo evolutivo que no lado do lado liberalismo ${ }^{13}$ irreverente.

Mas em matéria em que o Congresso legislou, os juízes e os tribunais convertem-se em submissas bouches de la loi. Talvez esse seja o maior paradoxo aparente na hierarquia das fontes do direito na common law, especiahnente para quem olha de fora, isto é, quem tem uma formação continental. Note-se bem, os juízes estẫo acima da doutrina, rectus, dos comentadores, mas não acina das leis. Os juízes ostentam grande poder e reputação social, mas não têm a mesma legitinidade democrática dos parlamentares, que, afinal, são os representantes do povo. Assim, se o juiz notteamericano, por un lado, parece ter mais poder do que ojuiz brasileiro, no sentido de que ojuiz norteamericano, mas do que o juiz brasileiro, cria e faz Direito, quando se avança para áreas do direito "prevenidas" pela legislação, o juiz norte-americano aparenta ter menos liberdade que o juiz brasileiro para interpretar e aplicar a lei; o juiz converte-se numa verdadeira bouche de la bi. A função do juiz, então, nãoé mais a de considerar razōes políticas (policy reasons) para decidirnum sentido ou no outro, mas sim a de emptegar as traditional tools of constnuction para determinar qual a intenção do Congresso (não a do legislator, mas a da legislature) e dar-lhe máxima eficácia. Não pode o juiz discordar ou criticar a vontade do Congresso - como alguns juízes brasileiros se acham, por vezes, no direito de fazer - sob pena de implodir-se o próprio sistema democrático, em que o povo através de seus mandatários, e não o juiz, faz as leis.

Como os juizes norte-americanos prendem-se aos fatos e como eles são comedidos ao teorizar. Todo dia, ao estudar, eu fazia a mesma coisa: avançava no meu inteminável casebooke sublinhava (i) de amarelo, os fatos relevantes (findings of fact) e as conclusóes de direito (holdings of law); (ii) de vermelho, o que me parecia ser law, istoé, o test ou ostandard fornulado e aplicado pelo juiz; e (iii) de verde, as digressóes filosóficas e as considerações políticas (policy reasons) dos juízes. Ah, mas como eu vibrava quando encontrava, ao meio de fatos e circunstâncias minuciosamente descritos, uma ou duas frases em que o juiz virava ora poeta, ora filósofo, invoca a policy reasons da norma, por vezes, para derrubá-la, por outras, para reforçál-la Como os juizes americanos eram comedidos! Nãose davam o direito de abstrair, ficavam presos aos fatos. Contudo, vez por outra, escapavam à ilação intelecriva, respiravam nas idéias gerais, buscavamo direito, um sentido ao caos da vida. Nesses exiguos momentos de desvario, ainda antes de fazerem o direito, de formularem o test ou standard que haveria de dar solução ao caso, transcendiamo direito, interrogavam as razóes políticas, buscavamnos fins da vida em sociedade as razões das normas. Eis os minutos mais felizes do meu dia. Os juízes norteamericanos não abusavam das teorias, faziam-nas contrastar com as pedras fáticas, resetvavam-lheso aroma fértil das flores que desabrocham. Nunca antes eu havia associado tão vividamente a felicidade

\footnotetext{
${ }_{13}^{3}$ Liberalismo aqui, por oposição a conservadorismo, emprega-se no sentido politico (e não econômico) de arrojo, assunçăo de riscos, mudança, revolução.
} 
coma ideação abstrata. Não foi nas orgias teóricas, mas nos pedregulhos concretos, que eu descobrio prazer da contemplaçăo das verdades abstratas e gerais, É na moderaçăo do prazer, em contínuo contraste com o sofrimento, que se acha a felicidade. Ohomem que esquece do sofrimento, não percebe o prazer, ainda que este aliesteja. Talvez aí se manifeste a sabedoria da common law.

A força da tradiçáo e a evolução, caso a caso, do direito. Parece-me que na common law, em comparação com a civil law, a tradição ocupa um lugar de maior proeminência na hierarquia axiológica que onienta e ordena as normas. Aqui a tradição é, de fato, uma segunda natureza, um argumentoem si. Afinal, aquilo que subsiste no tempo, que sobrevive às geraçōes, há de conter alguma verdade, algum valor, alguma sabedoria. Os juizes da common lau, destarte, pareceram-me menos temerários e mais prudentes ao proporem mudanças, na maioria das vezes, tão-só graduais, tímidas, medrosas, que visam antes à lenta e firme evolução que a rápida e oscilante revolução. Assim como hoje só de dá um passo avante após ár dua e rigorosa consideração, assim também se presume que o fora no passado, daí nascendo a força da tradição, que nada mais é do que uma presunção de prudência e circunspeção em relação aos que nos antecederam. Nada mais edificante do que valorizar e enaltecero trabal ho e devoção dos nossos predecessores; nada mais reconfortante do que saber que o nosso labor e sopesamento merecerão igual respeito e autoridade uma vez se imortalizem no tempo. Trata-se de um sistema que reconhece a experiência alheia, que não faz tabula rasa do que veio antes, que não rompe, e que caminha firme, mas prudente e vagarosamente, no caminho da justiça e eqüidade. Assim, parece traduzir o valor fundante da democracia que é a igualdade histónica, segundo oqual as geraçäes presentes nãosão necessariamente mais sálbias que as antetiores, não tendo legtínidade uma soluçâo que não parta ou não considere a experiência histórica, acumulada nos judicial precedents. A estabilidade enquanto manifestação de equuidade éacentuada pela vinculatividade das decisóes, as quais, por suavez, por terem assegurado maior perenidade einfluencia, tendema serem mais demorada e cuidadosamente redigidas. Assim, cada decisão renova, reescreve, redefine o direito; cada decisão adiciona algo de novo, é mais direito, ess porque se fala no state of the law, o estado do direito num determinado momento histórico, que se pode alterar com toda nova decisão judicial.

A common law é um sistema que se preocupa mais com o justo eqüitativo, caso a caso, do que com os enunciados gerais de justiça. Por essa mesma característica-a redefiniçăo do direito a cada decisão - se pode dizer que a common law, em certo sentido, é um sistema que se preocupa mais com ojusto eqüitativo, caso a caso, que comos enumciados gerais de justiça Nota-se que nenhum juiz se arrisca a formular regras gerais, que se aplicariam a todos os casos, muito antes pelo contrário; os juizes anglo-saxôes evitam toda e qualquer formulação geral, e quando elas se apresentam inevitáveis, fazem-nas con caveats e qualifications, que deixam ao juiz futuro uma porta aberta, uma possibilidade de não aplicar a regra vinculante do precedente, se the facts and circumstances of the case não o permitirem, ou se o resultado, com a aplicação, for iníquo. A justiça assimn não é concebida como aquilo que necessariamente vale para todos, mas como aquilo que, tendo em vista as característicase particularidades de cada caso, se mostra menos injusto no caso concreto. Assim, por exemplo, a regra que veda a um aluno cursar mais do que dez disciplinas pode não se aplicar a um outro aluno, se ojuiz, ao julgar o segundo caso com base no primeiro, que lhe serve de precedente, distinguir que no primeiro caso $o$ aluno destinatário da regrajudicial era um mau aluno e que o fato de ele ser uma mau aluno foi um fator relevante na decisão tomada pelo primeirojuiz eque no caso que agora the é dado decidiro 
alunoé um bom aluno eque esse fato, por ser relevante, fazo seu caso distinguir-se do primeiro, dandothe liberdade de conferir-the soluçăo diversa.

Na common law, predominam as soluçóes utilitaristas sobre as "essencialistas". A própria característica de prevalecer a justiça do caso concreto, em outras palavias, a que busca o que "funciona" melhor no caso particular, parece-meestar intimamente relacionada comoutra peculiatidade da common law: a predominância das soluçōes utilitaristas sobre as "essencialistas". " Essa constataçāo, contudo, não implica que a common law não reconheça valor da moral, da ética-proposição que, se formulada, parecer-me-ia inconciliável com o conteúdo de suas regras - mas sim que quando a solução utilitarista - aquela que mais viabiliza a consecução do resultado politicamente querido apresenta-se em conflito com a solução ético-moralista - que se preocupa com a preservaçẫo, e não admite a relativização, dos valores ético-morais - a primeiracostuma, na maiona das vezes, prevalecer. Por exemplo, uma disposição, tanto do Securties Act of $1933^{15}$ como do Securities Exchange Act of $1934^{16}$, que tem por objetivo concorrer para con que as sociedades de capital aberto divulguem suas projeçóes futuras, toma insancionável uma divulgação de má-fé (feita pelo diretor que tem conhecimento de sua falsidade), desde que tal informaçāo venha acompanhada de um disclaimer de que resultados futuros são imprevisiveis e que, por isso, as projeçóes divulgadas estão sujeitas a etro. Mas como pode, como neste caso, o direito amparar a má-fé deliberada? Em um sistema esencialista, que náo admite a relativização dos valores morais, tal norma seria inadmissivel, por incongruência em relação ao espínito que permeia todo o sistema. Na common law norte-americana, contudo, tal soluçãoé aceitável, já que o fim a que aspira a norma justifica o meio de que ela lança mão, mesmo que o meio aparente ser ou seja imoral. Cuida-se de um sistema que, nesse particular, parece priorizar os efeitos sociais sobre os fundamentos fllosóficos; tendência esta que ainda se verifica na admissão dos pronitive darnagese, em alguns Estados, do capital promishment, em que o indivídwo punido é visto como um instrumento a serviço do bem estar geral da comunidade. Aparenta-se aqui uma dissonância relativamente à posição kantiana - tão respeitada no nosso sistema jurídico-segundo a qual todo o indivíduo é um fim em si mesmo, não podendo ser usado como um meio à persecução de objetivos gerais que beneficiem toda a comunidade. Assim, a common law parece, nesse particular, discordar da nossa convicção de que o indivíduo tem um valor on tológico mínimo que não pode ceder em proveito da coletividade. Nesse sentido, poder-se-ia dizer que nós, da familia romano-germânica, seríamos mais individualistas, enquanto eles, da familia anglo-saxônica, mais coletivistas.

As mais tradicionais Universidades norte-americanas são privadas. Quando estive na Inglaterra e acompanhava as discussóes no Parlamento de Westminster a respeito da reforma da educação superior naquele país, um parlamentar trouxe à discussão uma pesquisa que procurava listar e ranquear as melhores Universidades do mundo. As sete prineiras, segundo aquela pesquisa inglesa, eram norte-americanas, todas privadas. Menciono isso porque talvez essa constatação, de que poucos possivelmente discordaniam, possa-nos sugerir que Universidade privada não é necessariamente sinônimo de mercantilização do ensino. Bem pelo contrário, os norte-americanos atribuem, em boa

\footnotetext{
" Para o efeito Ge, tão-somente, expressar a idéia que tenho em mente, diferenciaria as soluções utilitaristas das essencialistas com aquelas que nảo se justificam por si mesmas, mas pela finalidade a que estão direcionadas.

15 Section 27A.

is Section 25E.
} 
parte, às suas Universidades privadas o vigor de sua democracia e a engenhosidade de seu sistema econômico. Eles têm, até mesmo, um temor em relação à possibilidade de o Estado controlaro que as pessoas estudam e discutem; acreditam que a educação independente e imune à ingerência do Estado seja o último bastião da liberdade individual e da pluralidade democrática frente ao perigo constante da tirania. Diferentemente do que ocorre no Brasil, nos Estados Unidos, quanto mais cara a aution, mellhor tende a ser a Universidade (a não ser quando se comparam as piores privadas com as melhores públicas). Cuidadol Público, nos Estados Unidos, não quer dizer de graça. Afinal--e, pelo menos, é isso em que eles acreditam - nesta vida nada é de graça, tudo custa, tudo demanda trabalho (e o trabalho, enquanto sustentáculo da virude moral e da riqueza material, deve, logicamente, ser remunerado). Público, nos Estados Unidos, que dizer antes subsidiado. (Adverte-se que, aqui estamos nos restringindo tão-somente ao aspecto financeiro da distinção entre público e privado.) Nos Estados Unidos, ninguém se vê com o direito de educar-se gratuitamente, transferindo os custos de sua educação a outros que, por vezes, não se educam. Parece-me que, como os estudantes norte-americanos acumulam dívidas significativas ao longo de sua educação e devem começar a pagá-las assim que se estabelecen profissionalmente, acabam tendo eles uma noção mais correta de quando custa a sua educação, de quanto trabalho alheio ela demanda, e de quanto eles têm que se dedicar para fazer con o que o seu investimento se pague a longo prazo. Assim, acreditam que a gratuidadeé um convite ao desperdício, jáque, em tal hipótese, os alumos não sentiriam nos seus ombros os custos do investimento educacional e não se sentiriam, por via de conseqüência, tão comprometidos a aproveitá-lo ao máximo. Parece que muitas das escolhas políticas norte-ameticanas fundan-se na idéia republicana de que os individuos são capazes de prosperareme realizarem-se enquanto pessoa humana independentemente dopatemalismoestatal.

As leis norte-americanas são redigidas, freqüentemente, em linguagem confusa. Os estudantes de direito, nos Estados Unidos, via de regra, odeiam statutes. As matérias mais chatas são unanimemente as statutorily-based. A diversão está nos cases, nas matérias cuja fonte principalé common law. Eles dão graças a Deus por estudarem direito num pás de common law; pois - eles pensam - imagina como deve ser chato estudar direitonum país de civillaw, onde tudo que há éstatute? Eles teriam razão se as nossas leis fossem escritas tal qual o são os statutes deles. Que loucura! Há frases que se estendem por um parágrafo inteiro, com incontáveis unless, if, provided, notwithstanding. É precisolêlas tês vezes para compreendê-las en seu conjunto, ainda pulando e tapando as partes que não interessam ao caso concreto. Tudoé explicicado; nadaé deixado implícito. Até as coisas mais óbvias são ditas. Como olegislature näo quer deixar de fora nenhuma hipótese, acaba usando três, quatro, cinco sinônimos, os quais, no mais das vezes, querem dizer a mesma coisa. Não basta dizer inchuding, é preciso adicionar but not linited to, ou seja, é necessário lembrar, toda a vez, ao intérprete, que o termo including inclui mas não exclui. As đeffnições legislativas não definem, mas enfieiram uma lista quilométrica de sinônimos, dos mais evidentes aos mais bizarros. Por vezes, para deixar claro que uma hipótese é diferente daoutra, repete-se a frase inteira e alteram-se algumas palavras. As palavras nunca significam algo, mas significan algo para o efeito de um restrito dispositivo, capítulo ou diploma legral. As disposiçöes de direito processual freqüentemente entrelaçan-se com as de direito material. Dê una olhada no Clean Air Act, egaranto que você nunca mais vai querer ver um statute na sua frente! Se há uma coisa que nós, da ciuil law, sabemos fazer bemé redigit artigos de leis. O nosso Código Civil, por exemplo, chega a ser poético: 
O método socrático no ensino do direito nos Estados Unidos. Talvez o aspecto mais fascinante do ensino jurídico nos Estados Unidos seja o método socrático. Trata-se de um método que enfatiza a experiência, a dialética e o questionamento enquanto técnicas de desenvolvinento de habilidades intelectuais. É antes um método de motivação do que propriamente um método de transmissão do conhecimento. Visa ao desafio, à superação, à evolução intelectual autônoma. Os professores não se preocupam em dar repostas; pelo contrário, muitos costumam, como dizem os norteamericanos, esconder a bola (hide the ball). Eles questionam os alunos até que estes entrem em contradição ou dêem-se conta da fragilidade da tese que esposam. Neste sentido, leva ao niilismo, à negação da possibilidade de proposições não relativizáveis. Dáa impressão aos alunos de que estesnada sahem; e isso os leva a estudar cada vez mais, num ćrculo virtuoso. É um método que mexe profundamente com a auto-estima das pessoas, vez que sua ignorância é freqüentementeexpostaem público. Ele desafia, induz à secreção de adrenalina e ao aceleramento do ritmo cardíaco, que levao aluno ao limite de sua capacidade è contínua auto-superação. O nível de tenção nas autas socráticas é elevado, o aluno nunca sabe quando será chamado. Cada pergunta do professor, mesmo que direcionada a um colega, produz um novo frio na barriga, um novo suor nas mãos, um novo aperto no coração. O aluno tem que estar atento sempre, a cada palavta que o professor profere, pois aquele que, por distração ou falta de preparação, perde a linha de raciocinio do professor, pode estar correndo risco de vida. Orisco é tal que muitos colegas aconselham não comparecer à aula quando al uno năo estiver preparado, năo tiver feito todas as leituras, ou não se achar em condições de enfrentar a sétie apocalíptica de questionamentos caso venha a ser chamado. Enão é fácil seguir sempre a linha de pensamento do professor; o professor fala rápido, não repete as idéias, o conteúdo é denso, os casos são muitos, as situações labirínticas, háminades de detalhese sutlezas. Naverdade, só há uma maneira de conseguir acompanhar a aula: ter-se preparado, ter feito as leituress, respondido aos questionários, esmituçados os casos. Eis a inevitabilidade, a necessidade do estudo autônomo, da preparação prévia, não por uma questão de moralidade, por que eu acho que estudar é bom pra mim, mas por uma questão de sobrevivência, já que eu não saber uma resposta é uma derrota, afeta a minha reputação, a minha respeitabilidadee, alongoprazo, omeu sucessoprofissional econfortomaterial, numpaíseminentemente capitalista. Éum método que temmuito a ensinar sobre os instintos mais profundos dos serem humanos, sobre as nossas limitaçōes intelectuais e sobre quão pequenos nós somos diante das inquietações que provocamo nosso pensamento. É um métocdo, enfim, que só internaliza aquele que sofre nacarne e no osso a intensidade da experiência socrática.

O valor da moral e do fár play na educação jurídica nos Estados Ũnidos. No ensino juŕdico norte-ameticano, observa-se que a integridade moral está em pé de igualdade com habilidade técnica e a excelência intelectual. Seja pela ênfase que os professores dão em aula à postura ética do advogado, seja pelo código de honra que poucos antiscam quebrar, sob pena de terem de abandonar definitivamente a sua carreirajurídica. A honestidade acadêmicaé um valor absoluto, que se tonna universalmente respeitado em razão da severidade da condenaçăo (expulsão da escola e provável não aceitação por nenhuma outra). Trata-se de uma verdadeira ditadura dos justos e dos honestos!

O valor das notas (grades) para o sucesso na carreira jurídica. As notas e os conceitos que os alunos recebem de seus professores ao serem avaliados constituem um fator crucial para o seu sucesso profissional. Alguns chegam mesmo a dizer que um conceito A a mais ou a menos no boletim pode tesultar em US\$1.000 a mais ou a menos na remuneração dos primeiras empregos. Acredito que 
parte do valor que se atribui às notas esteja relacionado com a seriedade e a sofisticaçāo das avaliaçóes e com a honestidade acadêmica.

A "curva" e o valor da competição no ensino do direito nos Estados Unidos. A competitividade, enquanto fator motivacional da auto-superação contínua, é levada ao extremo pela existência da famosa "curva" na atribuiçãa de conceitos aos alunos de uma tuma. Assim, para que se tire o conceito máximo, não é suficiente que o aluno ultrapasse o padrão (threshold) de conhecimento para tanto exigido, mas que ele esteja entre os melhores alunos da sua turma. A nota, dessa forma, é dada sempre em relação à tumna. Em tetmos práticos, quando mais os teus colegas estudarem, mas tu terás que estudar para manter o mesmo conceito. Sob outra perspectiva, cada A a mais que há na turma, menores as tuas chances de ir tão bem quanto, pois o professor deve sempre manter uma distribuição de conceitos tal que a média da turma fique dentro de certos limites. Num exemplo simples, supondo que a média deve ser, em razão da curva, de 5 pontos por aluno que haja 10 alunos na turma, o professor teria à sua disposiçăo as seguintes altemativas, entre outras: (i) dar a nota 5 para os 10 alunos; (ii) dar a nota 10 para 5 alunos e a nota 0 para os 5 alunos restantes; (iii) dar a noca 8 para 2 alunos, a nota 6 para 2 alunos, a nota 5 para 2 alunos, a nota 4 para 2 alunos e a nota 2 para 2 alunos. Note-se que, em quaisquer dessas distribuições, a média de 5 pontos por aluno numa turna mantémse.

Conclusão. O que mais aprendi da minha experiência na Pace foi a convicção de que a educação é o único meio pelo qual se pode mudar o destino de um povo. Estou convencido da necessidade e da urgência de repensarmos o nosso sistema educacional, sob pena de, por nossa ineficiência e inércia, ficarmos cada vez mais dependentes dos países mais desenvolvidos. Se quisermos preservar, ou até mesmo recuperar, a nossa independência enquanto povo nossa soberania enquanto Estado, não temos outra altenativa senão repensarmos séria e profundamente o nosso sistema educacional, desde os seus pressupostos mais básicos até as suas técnicas mais avançadas. Acredito que a honestidade acadêmica, a competição conforme ao fair play e o desafio constante aos alunos para que se auto-superem insaciavelmente devam ser valores centrais. Acredito que o Convênio FIPSECAPES possa desempenhar um papel importante nessa nossa missão responsabilidade. 